\title{
Effects of Therapy on Rate of Absorption of Calcium from Gut in Disorders of Calcium Homoeostasis
}

\author{
J. REEVE， R. HESP， N. VEALL
}

British Medical fournal, 1974, 3, 310-313

\section{Summary}

A development of the double-tracer calcium absorption test, in which a function is derived for single-passage entry rate from the gut with time, has been assessed in various disorders of calcium homoeostasis. Single tests are diagnostically useful in calcium malabsorption but because of the wide spectrum of normal values a single test can only moderately enhance the accuracy of the diagnosis of hypercalcaemic states made primarily by other methods. On the other hand serial studies in the same subject can be much more informative because the test is normally highly reproducible if conditions are unchanged. Serial studies play an important part in assessing the efficacy of established methods of treatment in disorders of calcium homoeostasis and should be particularly helpful in studying the effects of new forms of therapy on the absorption process.

\section{Introduction}

The percentage absorption of an isotopically labelled calcium load given by mouth to normal subjects under standardized conditions varies widely (Dymling, 1971). Kinney et al. (1965) found that part of this variability was due to a marked negative regression of the fractional absorption on the current daily calcium intake of normal subjects as assessed by dietary history. The introduction by Ogg et al. (1968) of a single stool sample technique has made the test described by Kinney et al. of sufficient simplicity and low radiation hazard for routine diagnostic use.

Fuller characterization of the absorptive process in the clinical situation requires the use of a double-tracer technique. Scholer and Code (1954) were the first to derive timedependent functions describing the rates of transfer of water loads placed in the stomach and upper intestine. Hart and Spencer (1967) used similar techniques to measure the equivalent functions for ${ }^{47} \mathrm{Ca}$ and ${ }^{85} \mathrm{Sr}$. Their work was followed by that of Birge et al. (1969), who studied small numbers of normal volunteers and patients with a variety of disorders of calcium metabolism, and Szymendera et al. (1972), who studied a group of 20 normal subjects and a somewhat smaller group of osteoporotic patients, some before and others during the course of treatment.

In their normal group Szvmendera et al. found as wide a range of values for the maximal absorption rate (mean 0.90 $\mathrm{mg} / \mathrm{min}$, coefficient of variation 0.37 ) as for the percentage of the total dose absorbed (coefficient of variation 0.32 ). They also failed to show a significant difference between the treated and untreated osteoporotic group, though there was a difference between the mean values. In view of the high degree of reproducibility of the test under steady-state conditions (Avioli

\footnotetext{
Radioisotopes Division, Medical Research Council, Clinical Research Centre, Harrow, Middlesex HA1 3UJ

et al., 1965) we adopted the principle of using the patient as his own control where possible in these studies of calcium absorption. In all it was possible to perform repeat studies on five patients with proved hyperparathyroidism, two with osteomalacia, and three with osteoporosis. A number of other patients with these conditions and other disorders of calcium homoeostasis could be studied only once but nevertheless provided interesting data for comparison.

\section{Patients and Methods}

Patients (all over 40 years of age) on their usual diet were fasted overnight. When the test was not performed as part of the routine diagnostic procedure informed consent was obtained from the patient as laid down by the hospital ethical committee. After placement of an indwelling venous cannula up to $20 \mu \mathrm{Ci}{ }^{47} \mathrm{CaCl}_{2}$ was given by mouth with $100 \mathrm{mg}$ calcium chloride as carrier (Kinney et al., 1965). In two patients with osteoporosis the oral dose was given in $250 \mathrm{ml}$ milk made up to $300 \mathrm{mg}$ calcium as this was required by the protocol of a therapeutic trial in which they were participating. As the subject drank the dose $3-5 \mu \mathrm{Ci}{ }^{45} \mathrm{CaCl}_{2}$ in $5 \mathrm{ml}$ normal saline was injected intravenously. Blood samples $(8 \mathrm{ml})$ were taken through the indwelling cannula at 5, 10, $20,35,50,75,100,140,180,240,300$, and 360 minutes and 24 hours. Serum samples $(3 \mathrm{ml})$ together with $3 \mathrm{ml}$ of a $1 / 500$ dilution of the dose were then counted in a $7.5-\mathrm{cm}$ well-type scintillation counter or made up to $10 \mathrm{ml}$ with water and the Cerenkov radiations counted in a liquid scintillation beta-counter (Wallac Instruments Ltd.). The latter system proved to be of somewhat greater merit for samples of low activity.

After six weeks of frozen storage to allow for ${ }^{47} \mathrm{Ca}$ decay 2- $\mathrm{ml}$ serum aliquots were made up to $5 \mathrm{ml}$ with water and, after the addition of $10 \mathrm{ml}$ Unisolve 1 (Koch-Light Laboratories Ltd.), counted at $15^{\circ} \mathrm{C}$, together with ${ }^{45} \mathrm{Ca}$ and ${ }^{47} \mathrm{Ca}$ standards, in the liquid scintillation counter. Counts were corrected for the small ${ }^{45} \mathrm{Ca}$ contribution due to the initial $2-3 \%$ contamination in the ${ }^{47} \mathrm{Ca}$ dose. The oral and intravenous tracer curves were then expressed as a percentage of the dose per litre of plasma (fig. 1). The function describing the rate of calcium transfer into the plasma (spectrum of transit times) and the corresponding mean transit time $(\hat{t})$ were calculated as described by Love et al. (1973) using a computer program similar to that described by Hart and Spencer (1967). Percentage absorption was calculated in two ways-firstly, as the area under the spectrum of transit times curve and, secondly, as the ratio of oral to intravenous tracer plasma levels at times $t+i$ and $t$ respectively, where $t$ was more than four hours. In most cases detailed dietary histories were obtained within two weeks of the test.

\section{Results}

\section{HYPERCALCAEMIA}

Fourteen patients with hypercalcaemia (cases 1 to 14) were studied (see table). Nine were treated by parathyroidectomy and had biochemically and histologically confirmed hyperparathyroidism. A further two patients with a firm clinical and 


\begin{tabular}{|c|c|c|c|c|c|c|c|c|c|c|}
\hline \multirow{2}{*}{$\begin{array}{l}\text { Case } \\
\text { No. }\end{array}$} & \multirow{2}{*}{ Diagnosis } & \multirow{2}{*}{$\begin{array}{l}\text { Daily Dietary } \\
\text { Calcium Intake } \\
\text { (mg) }\end{array}$} & \multirow{2}{*}{$\begin{array}{c}\% \\
\text { Absorbed }\end{array}$} & \multirow{2}{*}{$\underset{\text { (min) }}{\text { Mean }}$} & \multicolumn{3}{|c|}{ Maximal Absorption } & \multirow{2}{*}{\multicolumn{3}{|c|}{$\begin{array}{c}\text { Repeat Time after Start } \\
\text { of Therapy }\end{array}$}} \\
\hline & & & & & Time (Min) & $\%$ Dose $/ \mathrm{Hr}$ & $\mathrm{Ca}(\mathrm{mg} / \mathrm{min})$ & & & \\
\hline $\begin{array}{r}1 \\
2 \\
3 \\
4 \\
5 \\
6 \\
7 \\
8 \\
9 \\
10 \\
11 \\
12 \\
13 \\
14 \\
15 \\
16 \\
17 \\
18 \\
19 \\
20 \\
21 \\
22 \\
23 \\
24\end{array}$ & $\begin{array}{l}\text { Hyperparathyroidism } \\
\text { ", } \\
\text { ”, } \\
\text { ”, } \\
\text { Malignant hypercalcaemia } \\
\text { Undiagnosed " } \\
\text { hypercalcaemia } \\
\text { Osteomalacia } \\
\text { ", } \\
\text { Osteoporosis } \\
\text { ", } \\
\text { (300 mg carrier) } \\
\text { ", " }\end{array}$ & $\begin{array}{r}850 \\
1,000 \\
800 \\
1,250 \\
1,200 \\
700 \\
620 \\
600 \\
700 \\
550 \\
1,100 \\
850 \\
1,250 \\
750 \\
<300 \\
650 \\
500 \\
480 \\
700 \\
1,650 \\
900 \\
1,100 \\
1,750 \\
1,200\end{array}$ & $\begin{array}{l}99(60) \\
74(77) \\
76(52) \\
55(77) \\
89(81) \\
100 \\
83 \\
76 \\
78 \\
87 \\
46 \quad 70 \dagger \\
56 \\
56 \\
39 \\
36(69) \\
38(88) \\
39 \\
52 \\
47(47) \\
57 \\
72 \\
49 \\
18(15) \\
25(28)\end{array}$ & $\begin{array}{l}33(100) \\
79(79) \\
86(63) \\
31(116) \\
39(58) \\
39 \\
81 \\
64 \\
77 \\
78 \\
125 \\
142 \\
138 \\
60 \\
124(43) \\
108(42) \\
118 \\
114 \\
47(49) \\
91 \\
98 \\
73 \\
111(99) \\
125(159)\end{array}$ & $\begin{array}{c}18(30) \\
25(25) \\
48(15) \\
18(18) \\
30(25) \\
25 \\
30 \\
30 \\
25 \\
60 \\
48 \\
90 \\
90 \\
25 \\
30(30) \\
25(25) \\
25 \\
30 \\
10(10) \\
30 \\
48 \\
18 \\
60(45) \\
90(90)\end{array}$ & $\begin{array}{c}210(22) \\
55(57) \\
54(35) \\
74(47) \\
160(81) \\
115 \\
52 \\
78 \\
46 \\
64 \\
16 \\
15 \\
26 \\
40 \\
13(110) \\
19(150) \\
17 \\
17 \\
79(82) \\
44 \\
31 \\
24 \\
8 \cdot 2(7 \cdot 8) \\
8 \cdot 4(6 \cdot 3)\end{array}$ & $\begin{array}{c}3.50(0.37) \\
0.92(0.95) \\
0.90(0.58) \\
1.23(0.86) \\
2.67(1.35) \\
1.92 \\
0.87 \\
1.30 \\
0.77 \\
1.07 \\
0.27 \\
0.25 \\
0.43 \\
0.67 \\
0.22(1.83) \\
0.32(2.50) \\
0.28 \\
0.28 \\
1.32(1.36) \\
0.73 \\
0.52 \\
0.40 \\
0.41(0.39) \\
0.42(0.37)\end{array}$ & $\begin{array}{l}4 \text { Months } \\
6 \text { Days } \\
1 \text { Year } \\
6 \text { Weeks } \\
3 \text { Months }\end{array}$ & $\begin{array}{l}\text { afte } \\
\text { "' } \\
\text { "' } \\
\text { "' }\end{array}$ & $\begin{array}{l}\text { eration } \\
\text { ", } \\
\text { ", } \\
\text { ", }\end{array}$ \\
\hline \multicolumn{5}{|c|}{ Normal range \pm 1 S.D. (Szymendera et al., 1972*) } & $16 \cdot 2 \pm 13 \cdot 1$ & & $0.90 \pm 0.35$ & & & \\
\hline
\end{tabular}

Figures in parantheses refer to repeat results on or after treatment.

Carrier load, including breakfast, varied' between 391 and $734 \mathrm{mg}$ calcium.

†First figure six-hour percentage absorption, second figure value at 24 hours.

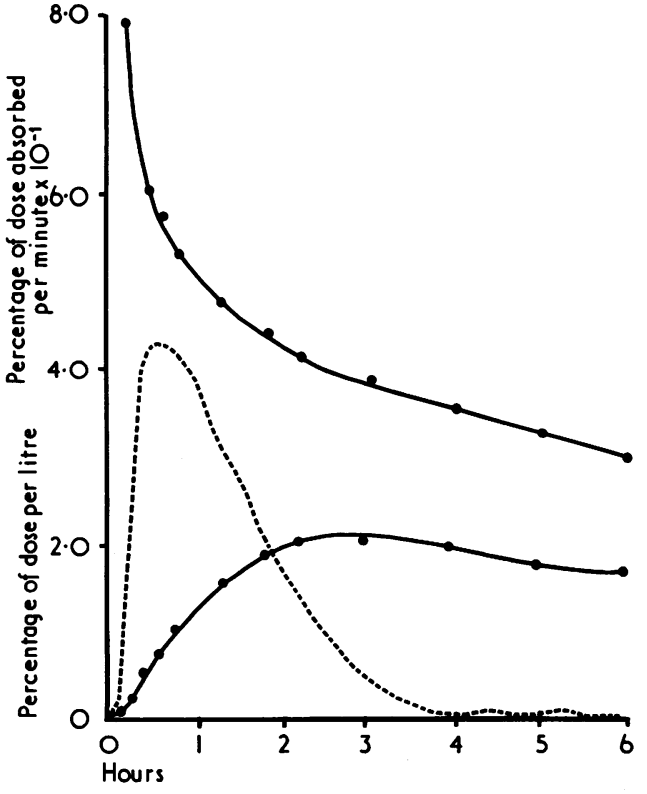

FIG. 1-Case 22, osteoporosis. Intravenous and oral tracer curves (upper and lower solid lines) and function describing rate of calcium transfer into plasma (dotted line).

biochemical diagnosis of hyperparathyroidism were treated conservatively. Of the remaining three patients one was not diagnosed and the other two had hypercalcaemia secondary to malignant deposits in the skeleton. Five of the surgically treated hyperparathyroid patients were studied twice. In the pretreatment hyperparathyroid group (cases 1 to 11) the percentage absorption of the dose after six hours ranged from $46 \%$ to $100 \%$ and the maximal absorption rate ranged from 0.27 to $3.50 \mathrm{mg} / \mathrm{min}$, there being excellent agreement between the two methods of calculating the percentage absorption. The patient with the lowest percentage absorption and lowest maximal absorption rate (case 11) showed radiological evidence of osteitis fibrosa cystica and osteomalacia (pseudofractures) and had an alkaline phosphatase level of 135 KingArmstrong units (KAU). The others all had alkaline phosphatase levels of 16 K.A.U. or less and showed no radio- logical evidence of osteitis or vitamin D deficiency. Because of the heterogeneity of the sample the results are not susceptible of formal statistical analysis; nevertheless, six of the patients had maximal absorption rates that fell within two standard deviations of the mean for normals given by Szymendera et al. (1972).

The repeat studies were all performed in the normocalcaemic state in patients who remained biochemically normal (fig. 2, left). In one patient restudied six days after parathyroidectomy (case 2) there was no significant change in the values estimated or the shape of the curve of the spectrum of transit times. In the other four, restudied six weeks to one year postoperatively, the mean drop in percentage absorption was $10 \%$ or the original value (it rose by $40 \%$ in one case and $5 \%$ in another) but in every case the maximal absorption rate fell, averaging $47 \%$ of the initial value on repeat study. There was, therefore, a definite tendency for the reduced early absorption to be compensated for, to a variable extent, by an increase in later absorption in the post-parathyroidectomized state.

The two patients with hypercalcaemia secondary to malignant skeletal deposits (cases 12 and 13) had low normal maximal transfer rates and mid-normal percentage absorptions.

\section{OSTEOMALACIA}

Four patients with osteomalacia were studied (cases 15 to 18), in two of whom it was possible to repeat the test six weeks after the initiation of therapy with calcium and vitamin $D$ tablets B.P.C. (500 U) 2 daily (fig. 2, right). In all the patients the maximal absorption rate was low, ranging from 0.22 to $0.32 \mathrm{mg}$ calcium $/ \mathrm{min}$. After treatment this value was increased eightfold in one case and tenfold in the other, while the percentage absorption was approximately doubled in both. The spectra of transit times after treatment had a similar appearance to those of hyperparathyroid patients before surgery (fig. 2, right).

\section{OSTEOPOROSIS}

Six patients with osteoporosis were studied (cases 19-24), three twice. One had had a previous gastrectomy, and border- 


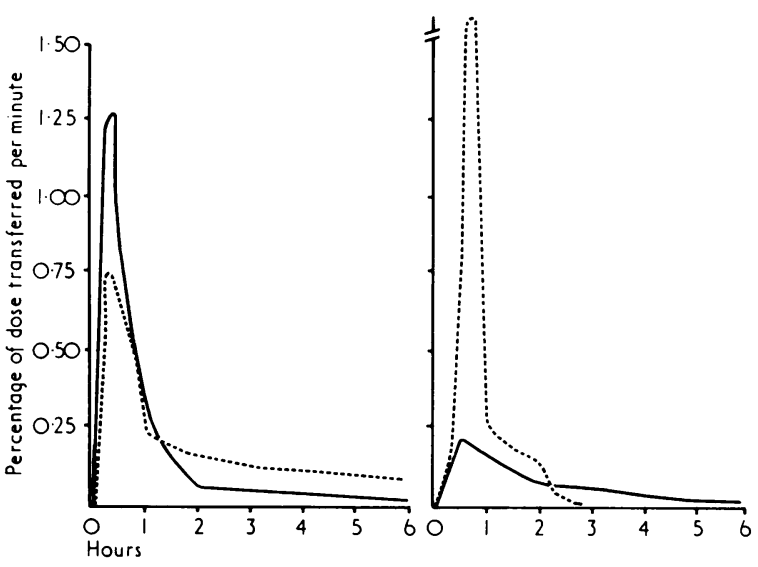

FIG. 2-Left: case 4, hyperparathyroidism. Spectra of transit times for calcium across gut wall. Solid line, before therapy. Dotted line, after parathyroidectomy. Right: case 15, nutritional osteomalacia. Spectra of transit times. Solid line, before therapy. Dotted line, after six weeks of replacement therapy. (Peak value $1.83 \%$ of dose/min.)

line vitamin $\mathrm{D}$ deficiency was suspected on dietary grounds. Replacement therapy ( $1,000 \mathrm{U}$ daily) made no difference to the calcium absorption test, nor did calcitonin therapy (50 U daily of porcine calcitonin, an initial stage in a wider trial) significantly alter the results in the two other patients in whom repeat studies were performed. All the results in this group lay within 1 S.E. of the mean of the normal range given by Szymendera et al. (1972) (fig. 3).

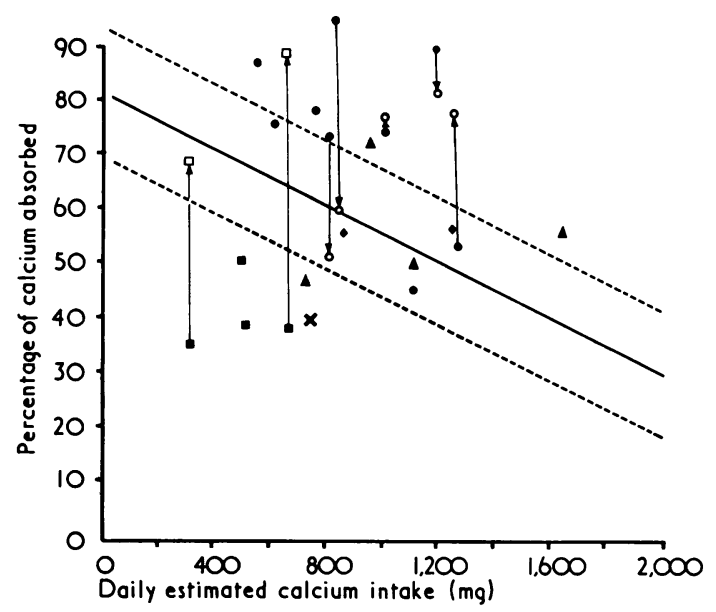

FIG. 3-Percentage absorptions (average of two methods) for patients listed in table superimposed on normal data according to Kinney et al. (1965). = hyperparathyroid. $\mathrm{O}=$ hyperparathyroid after parathyroidectomy. porosis. $=$ Malignant hypercalcaemia. $x=$ Undiagnosed hypercalcaemia.

\section{SIMULATION STUDIES}

An attempt was made to further interpret the paired results by using the physiological model of calcium absorption devised by Birge et al. (1969). A library of 100 simulated curves of the transit time spectrum was generated using the I.C.L. KALDAS analogue simulation program. Each curve in the library embodied a different combination of five rate constants and a fixed delay in mucosal transport controlling gastric emptying, movement of the unabsorbed fraction down the gut lumen, and absorption (early and late). Experimental results were then matched to the library of curves by eye, though it was difficult in some cases to make clear choices between two or three curves in the library which might cover a range of rate constants in combination.

In general it was found that the treatment of osteomalacia could be accounted for by a substantial increase in the early phase absorption rate constant, while treatment of hyperparathyroidism resulted in a decrease in the same rate constant, and in some cases a smaller rise in the late phase rate constant. One further consistent finding was that in this version of the test the rate constant governing stomach emptying was several-fold larger (and stomach emptying correspondingly faster) than with the procedure of Birge et al. (1969).

\section{Discussion}

The first aim in undertaking these investigations was to determine whether Hart and Spencer's (1967) improved double isotope absorption test could play a more important part in diagnosis. The second aim was to study both the pathological changes in absorption in disorders of calcium homoeostasis and the patterns of absorption in two therapeutic situations where positive calcium balance commonly occurs (Hosking et al., $1972 \mathrm{a}, \mathrm{b})$.

Though Szymendera et al. (1972) found a similar variation in peak absorption rate and percentage absorption in their normal group this does not rule out the possibility that the former may be a better diagnostic discriminant. Nevertheless, only three of the 24 patients presented here had peak absorption rates more than two S.D.s from the normal mean given by Szymendera et al. (1972), and all three gave abnormal test results as judged by the percentage of the dose absorbed. Clearly, the measurement of peak absorption rate is of much greater value when assessed in the light of other facts relating to the patient or in relation to a previous study.

Though the calcium absorption test has been used in the assessment of malabsorption states it has so far found very little place in the management of hyperparathyroidism. These studies have confirmed the characteristic pattern in most cases of hyperparathyroidism observed by Birge et al. (1969) and have further shown that this pattern changes noticeably after successful surgical treatment, implying that the test may be of use in the reinvestigation of surgically treated cases where the success of treatment is in doubt. A pattern of absorption before surgery more akin to that in osteomalacia, with a low peak absorption rate in spite of an eventual high percentage absorption (case 11), should alert one to the possibility of coexisting vitamin $\mathrm{D}$ deficiency, perhaps exacerbated by excess parathyroid hormone secretion (Woodhouse et al., 1971).

In previous studies in which this technique was used the oral calcium dose was given with breakfast or some other meal. The fact that in the version of the test used in these studies the dose passes more rapidly through the stomach is seen as an advantage, as the spectrum of transit times is correspondingly less influenced by individual variation in the rate of gastric emptying and therefore reflects more directly the rate of absorption from the small intestine.

Birge et al. (1969) suggested as a result of their simulation studies that the major part of the regulation of calcium absorption occurs distal to the duodenum. The fact that this conclusion could not be supported by our results may be the result of several factors which highlight the problems inherent in their approach. Firstly, there was a substantial difference in methodology. Secondly, the assumption of exponential stomach emptying of tracer may be in error. Thirdly, it is generally accepted that this form of parameter fitting should be treated with caution when applied to data with limited accuracy such as these. This last point was highlighted by the difficulties experienced in choosing the "best fit" to experimental data by eye from the library of curves.

These results are, however, compatible with the hypothesis that parathyroid hormone acts on the gut absorptive mechan- 
ism for calcium through the same final pathway as oral vitamin D (Wills, 1973). It is not yet clear whether in the one to four months after parathyroidectomy the reduction in "early phase" absorption is necessarily compensated for by an increase in "late phase" absorption as suggested by two of the three restudies conducted at that time. In any case a minority of parathyroidectomized patients fail to go into positive calcium balance postoperatively (Hosking et al., 1972 a).

In general it is evident that serial studies of the pattern of calcium absorption, particularly in relation to early and late absorption, are of considerable value, since significant changes in the handling of calcium by the gut are not necessarily demonstrable by simple measurements of overall absorption.

We wish to thank Miss P. Hulme and Mrs. C. Morgan for their thorough dietary assessments, and the sister and nurses of Haldane ward for their help in conducting the tests. Thanks are also due to
Mrs. G. James, Mr. J. D. Pearson, and Mr. G. P. Gibbs for skilled technical help.

\section{References}

Avioli, L. V., et al. (1965). Fournal of Clinical Investigation, 44, 128.

Birge, S. J., et al. (1969). Fournal of Clinical Investigation, 48, 1705.

Dymling, J. F. (1971). In Radioisotopes in Medical Diagnosis, ed. E. H. Belcher and $H$. Vetter, p. 298. London, Butterworth.

Hart, H., and Spencer, H. (1967). Proceedings of the Society for Experimental Biology and Medicine, 126, 365.

Hosking, D. J., Chamberlain, M. J., and Fremlin, J. H. (1972 a). Clinical Science, 43, 627

Hosking, D. J., et al. (1972 b). British Medical fournal, 1, 19

Kinney, V. R., Tauxe, W. N., and Dearing, W. H. (1965). Fournal of Laboratory and Clinical Medicine, 66, 187.

Love, A. H. G., et al. (1973). Clinical Science, 44, 267.

Ogg, C. S., Pearson, J. D., and Veall, N. (1968). Clinical Science, 34, 327.

Scholer, J. F., and Code, C. F. (1954). Gastroenterology, 27, 565

Szymendera, J., Heaney, R. P., and Saville, P. D. (1972). Fournal of Laboratory and Clinical Medicine, 79, 570.

tory and Clinical Medicine, 79,
Wills, M. R. (1973). Lancet, $1,820$.

Woodhouse, N. J. Y., Doyle, F. H., and Joplin, G. F. (1971). Lancet, 2, 283.

\title{
Acetanilide Oxidation in Phenylbutazone-associated Hypoplastic Anaemia
}

\author{
J. L. CUNNINGHAM， M. J. LEYLAND， I. W. DELAMORE， D. A. PRICE EVANS
}

British Medical fournal, 1974, 3, 313-317

\section{Eummary}

Acetanilide like phenylbutazone is paraoxidized by the liver endoplasmic reticulum as a primary biotransformation step. Both compounds were given at different times to each of 10 healthy volunteer subjects and the plasma disappearances measured. Correlation was shown between plasma clearance values of the two compounds $(r=+0.7067 ; P<0.05)$.

Eight patients with hypoplastic anaemia after phenylbutazone therapy were investigated. Plasma clearance values and half lives of acetanilide were measured in this group of patients and compared with those of a group of $\mathbf{3 0}$ healthy volunteer controls. There was a significant decrease in clearance $(P<0.01)$ and lengthening of half lives $(P<0.001$ in the patients with phenylbutazone-associated hypoplasia. Five patients with idiopathic aplastic anaemia-that is, without history of antecedent phenylbutazone ingestion-were similarly investigated with acetanilide and there was no significant difference between the results in these patients and those in the control group.

It is suggested that relatively poor paraoxidation of phenylbutazone producing high blood concentrations on a given dose may be a factor responsible for the drug-associated hypoplasia even though it does not explain the similar pattern of adverse reactions reported in association with oral administration of the metabolite oxyphenbutazone.

Nuffield Unit of Medical Genetics, Department of Medicine, University of Liverpool, Liverpool L69 $3 B X$

J. L. CUNNINGHAM, M.B., M.R.C.P., Wellcome Research Fellow

D. A. PRICE EVANS, M.D., F.R.C.P., Professor

University Department of Clinical Haematology, Manchester Royal Infirmary, Manchester M13 9WL

M. J. LEYLAND, M.R.C.P., Lecturer

I. W. DELAMORE, M.B., F.R.C.P., Consultant Physician

\section{Introduction}

A wide interindividual variation in the ability to oxidize, and therefore to eliminate from the body, phenylbutazone has been shown in man (Burns et al., 1953; Whittaker and Evans, 1970) Metabolism of this compound is controlled by both polygenic and environmental factors, and in one family study the genetic contribution has been estimated to be about $66 \%$ (Whittaker and Evans, 1970).

A serious complication of therapy with phenylbutazone is the appearance of bone marrow hypoplasia. Theoretically this could be due to accumulation of the parent compound or oxyphenbutazone, the major metabolite which is known to be toxic to bone marrow, or to the production of an unusual but toxic metabolite. Other factors involving marnow restponsiveness, the mechanisms of which are ill understood, could also operate.

This study was undertaken first to determine whether or not there was a correlation in a population of healthy subjects between oxidation rates of acetanilide and of phenylbutazone. Acetanilide was chosen as a particularly suitable compound for study because $84 \%$ of it is oxidized to $N$ acetyl p-aminophenol (paracetamol), and the hepatic endoplasmic reticulum inserts one atom of oxygen in the para position of the benzene ring (Brodie and Axelrod, 1948 a). Phenylbutazone is also oxidized in the para position of its benzene ring but undergoes other less important biotransformations including oxidation on the aliphatic side chain (Burns et al., 1955).

The second aim was to test the hypothesis that the marrow hypoplasia associated with phenylbutazone therapy might be due to accumulation of the parent compounds occurring in subjects who were relatively inefficient paraoxidizers and using acetanilide as a test drug. It was not possible to evaluate directly the role of phenylbutazone or its metabolites in patients with marrow hypoplasia, since it would have been unethical to re-expose patients to this drug.

\section{Control Subjects}

The 30 volunteer control subjects were healthy and drug 